\begin{tabular}{|c|c|}
\hline & $\begin{array}{l}\text { International Journal of Trend in Scientific } \\
\text { Research and Development (IJTSRD) }\end{array}$ \\
\hline 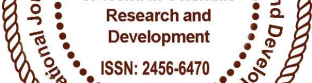 & International Open Access Journal \\
\hline 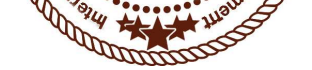 & ISSN No: 2456 - 6470 | www.ijtsrd.com | Volume - 2 | Issue - 2 \\
\hline
\end{tabular}

\title{
QSAR Modeling of Bisbenzofuran Compounds using 2D-Descriptors as Antimalarial Agents
}

Tripti Kaushal

Department of Chemistry, Technocrats Institute of Technology and Science, Bhopal, Madhya Pradesh

\author{
Anita K \\ Department of Chemistry, Career College, \\ Bhopal, Madhya Pradesh
}

Bashirulla Shaik

Dept. of Applied Science, National Institute of Technical Teachers Training and Research, Shamla Hills, Bhopal, Madhya Pradesh, India
Vijay K. Agrawal

Department of Chemistry, APS University, Rewa, Madhya Pradesh, India

\section{ABSTRACT}

In the present study we have performed Quantitative structure activity relationship (QSAR) analysis for 43bisbenzofuran derivatives to estimate the antimalarial activity using some 2D descriptors. Several significant QSAR models has been calculated for predicting the antimalarial activity $\left(-\log \mathrm{IC}_{50}\right)$ of these molecules by using the multiple linear regression (MLR) technique. Among the obtained QSAR models, a four parametric model was most significant having $\mathrm{R}^{2}=0.9502$. An external set was used for confirming the predictive power of the models. High correlation between experimental and predicted antimalarial activity values, was obtained in the validation approach that displayed the good modality of the derived QSAR models.

Keywords; bisbenzofuran derivatives, antimalarial activity, 2D descriptors, QSAR, MLR

\section{Introduction}

According to the World Health Organization (WHO), malaria is globally recognized as serious problem of public health, mainly in the tropical and subtropical regions of the world. Thus Malaria is an infectious disease which is caused by the protozoa of the genus Plasmodium. Commonly four species of the parasite cause infection, i.e., Plasmodium ovale, $P$. vivax, $P$. malariaeand $P$. Falciparum. Among them P.
Falciparum being the most virulent to humans. The introduction of parasites in human organism can be through the bite of a female Anopheles mosquito, and it can also be injection or transfusion of infected blood and through the hypodermic syringes. It effects $40 \%$ population of more than a hundred countries and considered as one of the diseases that caused already great damage to millions of people [1-5]. Due to this about 300 million cases and at least one million consequent deaths are estimated annually. About 40\% of malaria cases are registered in the world and about $90 \%$ deaths are mainly caused due to $P$. falciparum. For the treatment of malaria drugs such as chloroquine, mefloquine, pyrimethamine, dapsone, and cycloguanil are being used for years. But the resistance against malaria parasite strain is increasing continuously producing a big obstacle to chemotherapy of malaria disease[6-15].The massive use of classical antimalarials promoted fast selection of drug-resistant strains of $P$. falciparum, which requires an urgent development of new antimalarial drugs. Soidentification and design of novel drug molecules specifically affecting these targets could lead to better treatment of malaria. Recently the antimalarial activity of bisbenzofuran has generated interest among the drug researchers which has displayed activityagainst several strains of malaria. It has limited role to treat the diseases because of 
protonation of its amidine group at physiological $\mathrm{pH}$, pentamidineand also shows low oral availability. Drugrequiresparentral administration which makes the treatment less practical in rural areas. Pentamidine is tolerated by most patients in spite of some reported serious adverse effects $[16,17,18]$.In this context it is very appropriate to search for options to find a potent antimalarial compound with improved potency and oral availability. Computational chemistry is an important tool to rational drug design. The quantitative structure-activity relationship (QSAR) approach by Hansch et al. helps to correlate the specific biological activities of compounds with the molecular properties of the compounds. The authors have successfully reported use of topological parameters for modeling antimalarial activity of 4pyridones against $P$. falciparum T9-96 strains[ 19].

\section{Materials and Methods}

In the present work an attempt was made to find out a mathematical model which correlates the possible structural requirements and biological activity of in order to design of new and more potent compounds with strengthened biological activities. An analysis using the MLR method is applied to a series of 43bisbenzofurans derivatives with known biological activity[20].The biological activity has been given in terms of negative $\log$ of $\mathrm{IC}_{50}$ in order to convert the data into free energy change related values.

Structural details of the compound having antimalarial activity (bisbenzofurancation) used in present studyare given in Table-1.The parameters used for modeling the activity are VE1_D, VE1_B(e), GATS7p, GATS8p, CATS2D_04_DA, CATS2D_06_PL, B10[N-N], F08[C-C], DLS_07, Psychotic-80 and cRo5. Here DLS_07, Psychotic-80, cRo5 are Drug-like indices descriptors, CATS2D_04_DA, CATS2D_06_PL, B10[N-N], F08[C-C] are 2D Atom Pairs parameters, GATS7p, GATS8p are 2D- autocorrelation parameters [21] and VE1_D, VE1_B(e) are 2D matrix-based descriptors. All these have been calculated using DRAGON software[22] and for regression purpose NCSS was used [23]. The calculated values along with biological activity $-\log \mathrm{IC}_{50}$ are given inTable-2.The entire data set given in table 1 has been divided into training and test set and efforts have been made for obtaining the best suitable model for modeling the $-\log \mathrm{IC}_{50}$ value. We have taken 31 compounds for training set and 12 compounds as test set. The generation of training and test sets is done on random basis. For statistical validation, variety of statistical parameters was calculated. All these statistically significant correlation models for the training set have been reported below along with their statistical parameters.

\section{RESULT AND DISCUSSION:}

The correlation matrixes of these parameters arereportedin Table-3 which clearly reveals that F08[C-C] is highly correlated with VE1_D and similarly $\mathrm{B} 10[\mathrm{~N}-\mathrm{N}]$ is highly correlated with CATS2D_06_PL and Psychotic-80 is highly correlated F08[C-C]. Hence while dealing with these parameters the collinearity defect should be checked.

Now, we will discuss the results obtained in successive regression analysis. It is pertinent to mention that the parameter which are auto-correlated should not be used in multiparametric analysis because they may result in to some defect in the model.

Through variable selection four parameters were selected and the data presented in Table-2 was subjected to regression analysis which yields significant models. These models along with their quality are reported in Table-5.

\section{ONE-PARAMETRIC MODEL:}

Among all the models, the best one parametric model contains $\mathrm{B} 10[\mathrm{~N}-\mathrm{N}]$, having $\mathrm{R}^{2}$ value equal to 0.8459 . The model is as below:

$-\log \mathrm{IC}_{\mathbf{5 0}}=2.0051( \pm 0.1589) \mathrm{B} 10[\mathrm{~N}-\mathrm{N}]+0.1149$

$\mathrm{N}=31, \mathrm{Se}=0.1563, \mathrm{R}^{2}=0.8459, \mathrm{R}_{\text {Adj }}^{2}=0.8406, \mathrm{~F}-$ ratio $=159.185, \mathrm{Q}=5.8830$

Here and here after $\mathrm{N}$ is total number of compounds ; Se is the standard error of estimation; $\mathrm{R}^{2}$ is the square of correlation coefficient; $R^{2}$ Adj is the adjusted $R^{2} ; F$ is the Fisher's ratio and $\mathrm{Q}$ is the Pogliani's quality factor[24] which is the ration of $\mathrm{R} / \mathrm{Se}$ (Pogliani, 1994,1996)

\section{TWO-PARAMETRIC MODEL:}

When cRo5 is added to the mono-parametric model, two parametric models are resulted with improved $\mathrm{R}^{2}$ value. For this model $\mathrm{R}^{2}$ comes out to be 0.9211 and $\mathrm{R}^{2}$ Adj also enhances from 0.8406 to 0.9154 . The model is reported as under
$\mathbf{I C}_{50}=2.0531( \pm 0.1161)$
cRo5 +0.3550
$\mathrm{B} 10[\mathrm{~N}-\mathrm{N}]-0.2881( \pm 0.0558)$
$\mathrm{N}=31, \mathrm{Se}=0.1138, \mathrm{R}^{2}=0.9211, \mathrm{R}_{\mathrm{Adj}}^{2}=0.9154, \mathrm{~F}-$ ratio $=163.392, \mathrm{Q}=8.4292$ 


\section{THREE-PARAMETRIC MODEL:}

F08[C-C] has also been found to be an effective parameter in modeling $\log \mathrm{IC}_{50}$. When higher parametric models were tried with B10_N_N, F08[C-C]as correlating parameters along with VE1_D in modeling the antimalarial activity, a improvement in the quality of the model is observed. For this model, $\mathrm{R}^{2}$ comes out to be 0.9318 . The value of $\mathrm{R}^{2}$ Adj changes from 0.9154 to 0.9242 suggesting that the added parameter is favorable . The model is given below:

IC $_{50}=2.1541( \pm 0.1176) \quad$ B10_N_N_+0.0241 $( \pm 0.0044)$ F08[C-C]-0.5575( \pm 0.1052$) \mathrm{VE} 1 \_\mathrm{D}+2.2910$

$\mathrm{N}=31, \mathrm{Se}=0.1078, \mathrm{R}^{2}=0.9318, \mathrm{R}_{\mathrm{Adj}}^{2}=0.9242, \mathrm{~F}-$ ratio $=122.890, \mathrm{Q}=8.9532$

\section{FOUR -PARAMETRIC MODEL:}

Finally, by adding 2D- autocorrelation parametersGATS7p atetra - parametric model having $\mathrm{R}^{2}=0.9502$ is found to be the best model for modeling $\mathrm{IC}_{50}$ activity. The model contains B10 [N-N], F08[CC], GATS7p and VE1_D as correlating parameter. The lowest values of SE and also highest value of $F$ ratio and Q-value further confirm our results. Addition of GATS7p is justified as $\mathrm{R}^{2}$ Adj $/$ changes from 0.9242 to 0.9425 . The model is found as under:
$\mathbf{I C}_{\mathbf{5 0}=1.9399 \quad( \pm 0.1235)}$
$( \pm 0.0041)$
$\mathrm{B} 10[\mathrm{~N}-\mathrm{N}]+0.0197$

GATS7p $-0.5498( \pm 0.0916)$ VE1 D +3.3488

$\mathrm{N}=31, \mathrm{Se}=0.0939, \mathrm{R}^{2}=0.9502, \mathrm{R}_{\text {Adj }}^{2}=0.9425, \mathrm{~F}-$ ratio $=124.031, \mathrm{Q}=10.3859$

A close look at this model revels that out of four parameters contained, two (GATS7p, VE1_D) are having negative coefficients, while two of them are positive (B10 $[\mathrm{N}-\mathrm{N}], \quad \mathrm{F} 08[\mathrm{C}-\mathrm{C}])$. The predictive potential of the model has been obtained by plotting a graph between observed and estimated activity values and such graph is demonstrated in Fig. 1.

\section{PREDICTIVE POWER BASED ON CROSS VALIDATION:}

Leave -one -out cross (leave -one -out) validation procedure"(Chaterjeeet al .2000) is being widely used to examine the suitability of predictive power of the model[25]. The obtained results are reported in Table-6 .As stated earlier the predicted residual sum of square (PRESS) is the most important crossvalidation parameter accounting for good estimate of the real predictive error of the model. Its value less than SSY (sum of squares of response value) indicates that the model predicts better than the chance and can be considered statically significant. In our study, the value of PRESS is much lower than SSY indicating that all the models obtained are statically significant. The ration of PRESS/SSY can be used to calculate approximate confidence intervals of prediction of new compounds. To be a reasonable and significant QSAR model, the ratio PRESS/SSY should be less than 0.4 $(\mathrm{PRESS} / \mathrm{SSY}<0.4)$ and the value of this ratio 0.1 indicates an excellent model. A close observation of Table- 6 shows that except the one parametric model (model1, Table4)all other models have the PRESS/SSY ratio more or less or nearer to 0.1 indicating thereby all the proposed models are having best predicting capacity.

$\mathrm{R}_{\mathrm{cv}}^{2}$ is the cross validation squared correlation coefficient. The highest $R^{2}$ vv values 0.948 for four parametric model [(Model-30 and Table-4);Fig.1] confirms our findings. The two important crossvalidation parameters uncertainty in prediction (S PRESS) and predictive squared error (PSE) were also calculated. For this model, the value of SSY is highest, whereas, the values of PRESS, PRESS/SSY, SPRESS, and PSE have been lowest, conforming our findings.

Final confirmation is obtained by calculating the estimated values of $-\log \mathrm{IC}_{50}$ for the entire set of compounds using tetra parametric model and the same has been reported in Table-5. These values are in good agreement with the estimated value. Further confirmation is obtained by plotting a graph between observed and estimated $-\log \mathrm{IC}_{50}$ values using four parametric model, the predictive power for the model comes out to be 0.9502 , suggesting that $95 \%$ variance in the data could be explained using this model. Therefore, this is the best model for modeling iogIC 50 values of the compound used in this study. The external predictive power of the model is assessed by predicting pIC50 value of the 9 test set molecules, which are not included in the QSAR model development.

Further, VIF (variance inflation factor), Eigen values $(\lambda \mathrm{i})$, condition number $(\mathrm{k})$, tolerance $(\mathrm{T})$ for all the independent parameters have been calculated or all the independent parameters used in the proposed models and they are reported in Table-7.The collinearity is observed if the value of VIF is greater than 10. In the table all the combination have VIF less 
than 10 means all the proposed models are free from collinearity. And if $\lambda \mathrm{i}$, (Eigen value) is found to be greater than 5 then the model will suffer from collinearity. Here all the models have $\lambda i$ value less than 5 so all the models are free from the defect of collinearity. Condition number is another test forcollinearity if its value is found to be $>100$ then the collinearity exists but results indicate that values always $<100$ likewise. . Tolerance value equal to 1 or less indicates absence of collinearity Table-7 indicates that all the above mentioned parameters or models discussed in the study are free from multi-collinearity. The ridge traces are recorded in fig. -2 and fig. -3 respectively.

\section{CONCLUSION:}

1. Positive coefficient of $\mathrm{B} 10[\mathrm{~N}-\mathrm{N}]$ suggests that presence/absence of $\mathrm{N}-\mathrm{N}$ at topological distance 10 plays a dominant role in deciding the antimalarial activity of present set of compounds.

2. The coefficient of both the GATS7p and VE1_D parameters are negative. Therefore molecules having higher value of polarizability and topological distance matrix should be avoided in designing synthesizing new compounds for better activity. Compounds with low value of these parameters will certainly give better activity.

Table 1 Structures of bisbenzofurancation used in the present study

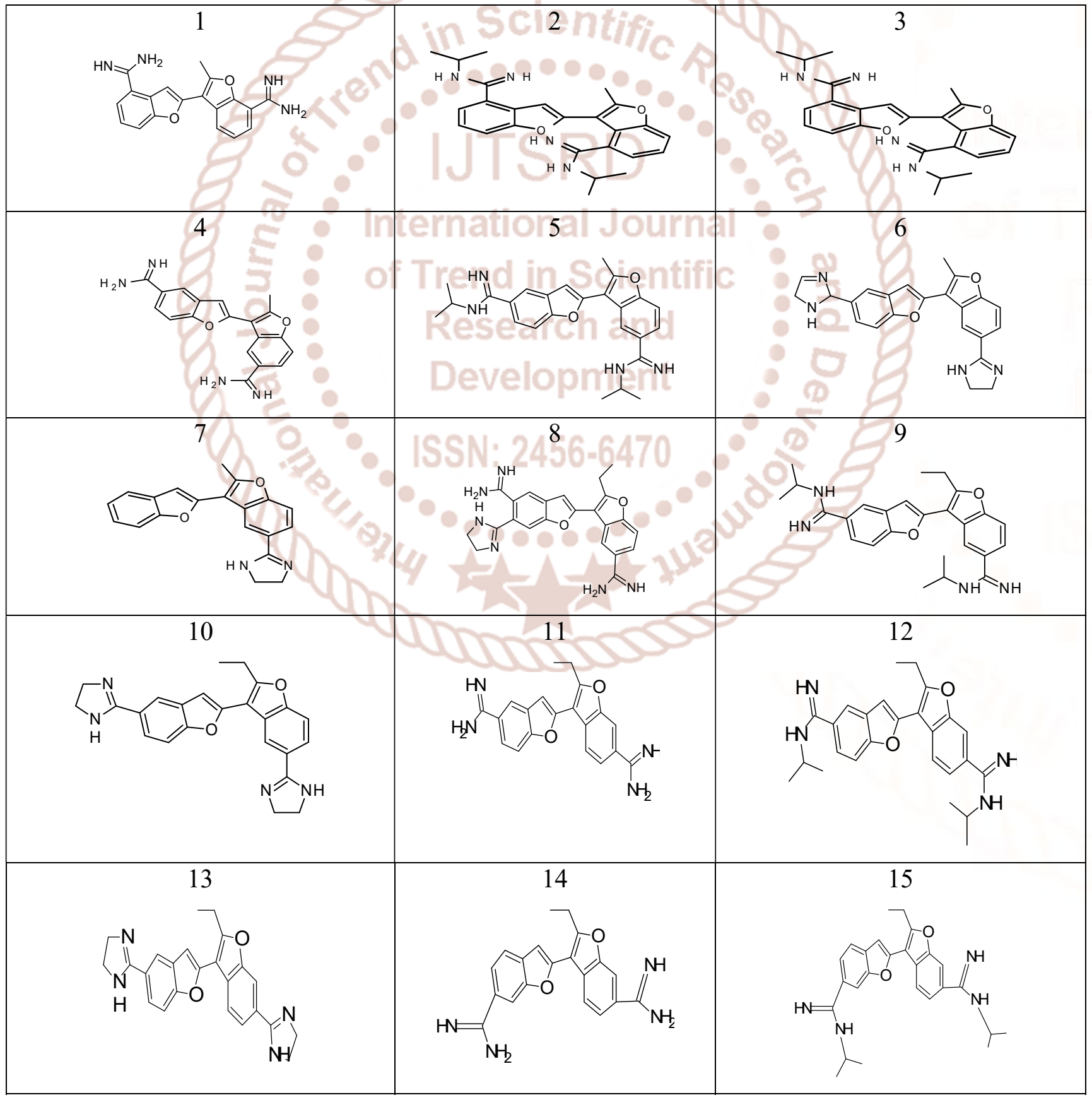


International Journal of Trend in Scientific Research and Development (IJTSRD) ISSN: 2456-6470

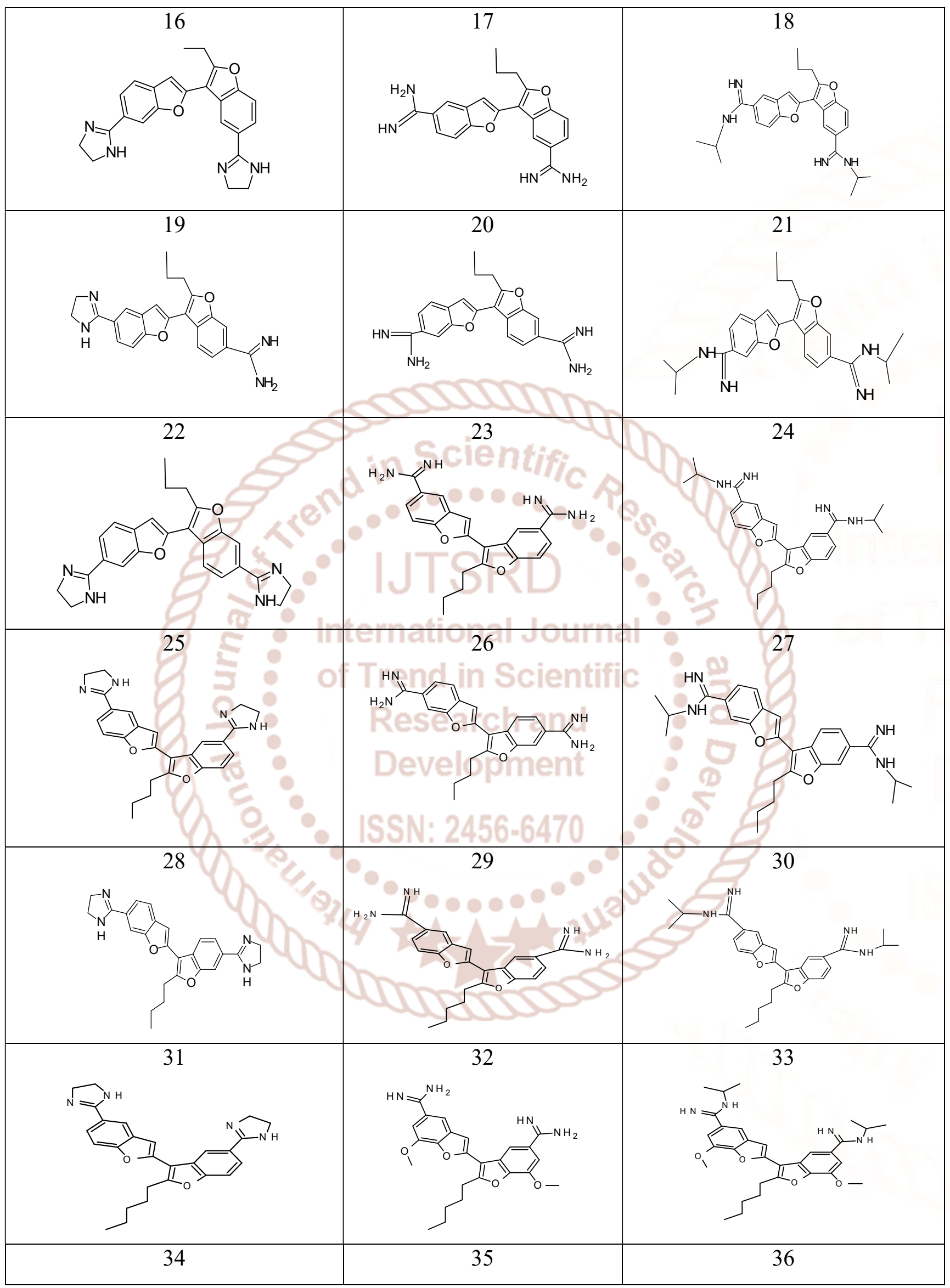


International Journal of Trend in Scientific Research and Development (IJTSRD) ISSN: 2456-6470

(n)

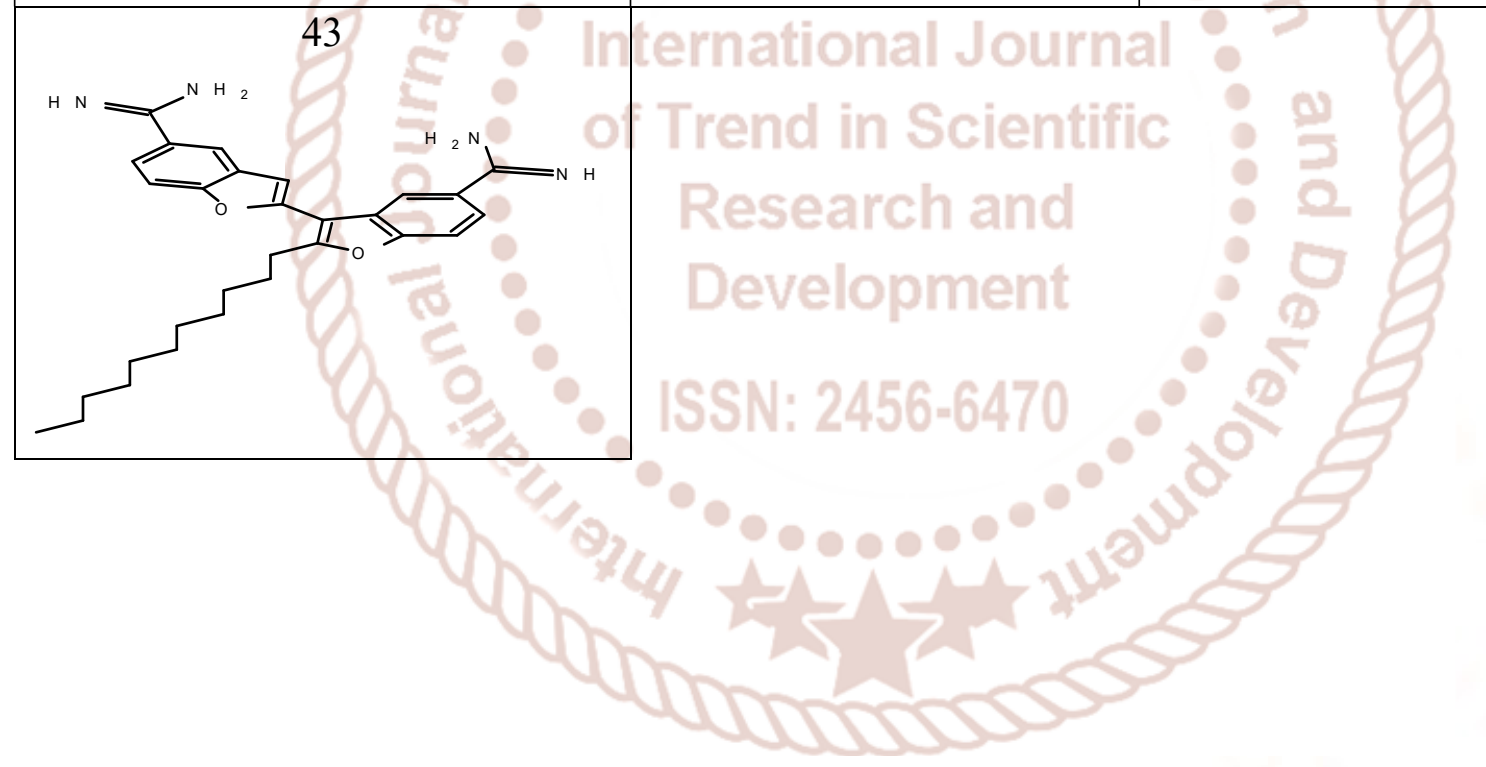


International Journal of Trend in Scientific Research and Development (IJTSRD) ISSN: 2456-6470

Table -2 values of the calculated descriptors along with their activity values

\begin{tabular}{|c|c|c|c|c|c|c|c|c|c|c|c|c|}
\hline \begin{tabular}{l|} 
S. \\
No.
\end{tabular} & $\mathrm{IC}_{50}$ & $\overline{\text { VE1_D }}$ & $\begin{array}{c}\text { VE1_B } \\
\text { (e) }\end{array}$ & GATS7p & GATS8p & $\begin{array}{c}\text { CATS2D } \\
\text { 04_DA }\end{array}$ & $\begin{array}{c}\text { CATS2D } \\
\text { 06_PL }\end{array}$ & $\begin{array}{c}\text { B10 } \\
{[\mathrm{N}-\mathrm{N}]}\end{array}$ & $\begin{array}{c}\mathrm{F} 08 \\
{[\mathrm{C}-\mathrm{C}]}\end{array}$ & DLS_07 & $\begin{array}{c}\text { Psychotic- } \\
80\end{array}$ & cRo5 \\
\hline $1 *$ & 0.068 & 4.617 & 4.07 & 0.978 & 1.078 & 2 & 2 & 0 & 10 & 1 & 1 & 1 \\
\hline $2 *$ & 0.918 & 5.084 & 4.05 & 1.13 & 1.092 & 0 & 0 & 1 & 21 & 1 & 1 & 1 \\
\hline 3 & 2.12 & 4.647 & 3.939 & 0.917 & 1.14 & 0 & 3 & 1 & 11 & 1 & 1 & 1 \\
\hline $4 *$ & 0.028 & 4.541 & 3.844 & 1.087 & 1.054 & 0 & 0 & 0 & 11 & 1 & 1 & 1 \\
\hline 5 & 0.102 & 4.987 & 3.941 & 1.047 & 1.102 & 0 & 0 & 0 & 20 & 1 & 1 & 1 \\
\hline 6 & 0.034 & 4.843 & 3.789 & 1.14 & 0.98 & 0 & 0 & 0 & 17 & 1 & 1 & 1 \\
\hline 7 & 0.022 & 4.294 & 3.641 & 1.127 & 1.032 & 0 & 0 & 0 & 12 & 1 & 1 & 1 \\
\hline 8* & 0.003 & 5.131 & 3.844 & 0.987 & 1.06 & & $\Omega$ & 0 & 18 & 0.5 & 1 & 1 \\
\hline 9 & 0.003 & 5.045 & 3.962 & 1.044 & 1.153 & 0 & 0 & 0 & 22 & 1 & 0 & 1 \\
\hline 10 & 0.011 & 4.908 & 3.909 & 1.115 & 1.028 & 0 & 0 & 0 & 19 & 1 & 1 & 1 \\
\hline 11 & 0.002 & 4.599 & 3.892 & 1.144 & 1.223 & 0 & 1 & 0 & 13 & 1 & 1 & 1 \\
\hline 12 & 0.006 & 5.038 & 3.99 & 1.082 & 1.087 & 0 & 0 & 0 & 22 & 1 & 0 & 1 \\
\hline 13 & 0.046 & 4.894 & 3.935 & 1.071 & 1.09 & 0 & 0 & 0 & 19 & 1 & 1 & 1 \\
\hline 14 & 0.004 & 4.599 & 3.728 & 1.236 & 1.176 & 0 & 2 & 0 & 13 & 1 & 1 & 1 \\
\hline 15 & 0.005 & 5.038 & 3.817 & 1.104 & 0.96 & 0 & 0 & 0 & 24 & 1 & 0 & 1 \\
\hline 16 & 0.034 & 4.908 & 3.761 & 1.012 & 1.161 & 0 & 0 & 0 & 19 & 1 & 1 & 1 \\
\hline $17 *$ & 0.041 & 4.714 & 3.873 & 1.109 & 1.118 & $S S Q 0 \| C$ & 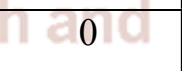 & 0 & 16 & 1 & 1 & 1 \\
\hline $18 *$ & 0.009 & 5.109 & 3.97 & 1.071 & 1.135 & $\mathrm{EV} 0 \mathrm{OP}$ & mont & 0 & 25 & 1 & 0 & 1 \\
\hline 19* & 0.004 & 4.866 & 3.873 & 1.224 & 1.081 & 0 & 1 & 0 & 18 & 1 & 1 & 1 \\
\hline 20 & 0.037 & 4.683 & 3.736 & 1.256 & 1.142 & U & 2 & 0 & 16 & 1 & 1 & 1 \\
\hline 21* & 0.036 & 5.095 & 3.825 & 1.127 & 0.969 & 0 & 0 & 0 & 27 & 1 & 0 & 1 \\
\hline 22 & 0.353 & 4.958 & 3.784 & 1.006 & 1.194 & 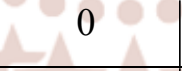 & 0 & 0 & 22 & 1 & 1 & 1 \\
\hline $23 *$ & 0.032 & 4.817 & 3.877 & 1.145 & 1.15 & 0 & 0 & 0 & 20 & 1 & 1 & 1 \\
\hline 24 & 0.01 & 5.182 & 3.974 & 1.097 & 1.157 & 0 & 0 & 0 & 29 & 1 & 0 & 1 \\
\hline 25 & 0.026 & 5.062 & 3.922 & 1.168 & 1.057 & 0 & 0 & 0 & 26 & 1 & 1 & 1 \\
\hline $26 *$ & 0.058 & 4.779 & 3.74 & 1.282 & 1.171 & 0 & 2 & 0 & 20 & 1 & 1 & 1 \\
\hline 27 & 0.076 & 5.159 & 3.829 & 1.152 & 1.004 & 0 & 0 & 0 & 31 & 1 & 0 & 1 \\
\hline $28 *$ & 0.164 & 5.031 & 3.788 & 1.043 & 1.213 & 0 & 0 & 0 & 26 & 1 & 1 & 1 \\
\hline 29 & 0.067 & 4.926 & 3.878 & 1.087 & 1.181 & 0 & 0 & 0 & 23 & 1 & 1 & 1 \\
\hline 30 & 0.02 & 5.266 & 3.976 & 1.063 & 1.18 & 0 & 0 & 0 & 32 & 0.5 & 0 & 1 \\
\hline 31 & 0.067 & 5.156 & 3.923 & 1.118 & 1.088 & 0 & 0 & 0 & 29 & 1 & 0 & 1 \\
\hline 32 & 0.066 & 5.329 & 3.861 & 1.06 & 1.043 & 0 & 0 & 0 & 29 & 0.5 & 1 & 1 \\
\hline 33* & 0.133 & 5.661 & 3.945 & 1.025 & 1.129 & 0 & 0 & 0 & 42 & 0.5 & 0 & 1 \\
\hline 34 & 0.11 & 5.56 & 3.9 & 1.041 & 1.161 & 0 & 0 & 0 & 35 & 1 & 0 & 1 \\
\hline
\end{tabular}


International Journal of Trend in Scientific Research and Development (IJTSRD) ISSN: 2456-6470

\begin{tabular}{|l|l|l|l|l|l|l|l|l|l|l|l|l|}
\hline $\mathbf{3 5}$ & 0.057 & 4.888 & 3.741 & 1.214 & 1.202 & 0 & 2 & 0 & 23 & 1 & 1 & 1 \\
\hline $\mathbf{3 6}$ & 0.018 & 5.233 & 3.83 & 1.115 & 1.037 & 0 & 0 & 0 & 34 & 0.5 & 0 & 1 \\
\hline $\mathbf{3 7}$ & 0.133 & 5.116 & 3.789 & 0.998 & 1.237 & 0 & 0 & 0 & 29 & 1 & 0 & 1 \\
\hline $\mathbf{3 8}$ & 0.364 & 4.989 & 3.879 & 1.056 & 1.125 & 0 & 0 & 0 & 26 & 1 & 1 & 1 \\
\hline $\mathbf{3 9}$ & 0.279 & 4.822 & 3.879 & 1.049 & 1.093 & 0 & 0 & 0 & 27 & 1 & 0 & 0 \\
\hline $\mathbf{4 0}$ & 0.694 & 4.419 & 3.879 & 1.042 & 1.084 & 0 & 0 & 0 & 28 & 1 & 0 & 0 \\
\hline $\mathbf{4 1}$ & 0.296 & 4.674 & 3.879 & 1.037 & 1.076 & 0 & 0 & 0 & 29 & 0.5 & 0 & 0 \\
\hline $\mathbf{4 2}$ & 0.287 & 4.952 & 3.879 & 1.032 & 1.069 & 0 & 0 & 0 & 30 & 0.5 & 0 & 0 \\
\hline $\mathbf{4 3}$ & 0.219 & 5.146 & 3.879 & 1.028 & 1.063 & 0 & 0 & 0 & 31 & 0.5 & 0 & 0 \\
\hline
\end{tabular}

VE1_D =coefficient sum of the last eigenvector from topological distance matrix (2D matrix-based descriptors) VE1_B $(e)=$ coefficient sum of the last eigenvector from Burden matrix weighted by Sanderson electronegativity( 2D matrix-based descriptors)

GATS7p = Geary autocorrelation of lag 7 weighted by polarizability (2D autocorrelations)

GATS8p $=$ Geary autocorrelation of lag 8 weighted by polarizability (2D autocorrelations)

CATS2D_04_DA=CATS2D Donor-Acceptor at lag 04 (CATS 2D)

CATS2D_06_PL= CATS2D Positive-Lipophilic at lag 06 CATS (2D Atom Pairs)

$\mathrm{B} 10[\mathrm{~N}-\mathrm{N}]=$ Presence/absence of $\mathrm{N}-\mathrm{N}$ at topological distance 10 (2D Atom Pairs)

$\mathrm{F} 08[\mathrm{C}-\mathrm{C}]=$ Frequency of $\mathrm{C}-\mathrm{C}$ at topological distance 8 (2D Atom Pairs)

DLS_07= modified drug-like score from Veber et al. (2 rules)( Drug-like indices)

Psychotic-80= Ghose-Viswanadhan-Wendoloski antipsychotic-like index at 80\% (Drug-like indices)

cRo5 $=$ Complementary Lipinski Alert index (Drug-like indices)

Table 4.1.3 Correlation matrix

\begin{tabular}{|c|c|c|c|c|c|c|c|}
\hline & IC 50 & VE1_D & VE1_B(e) & GATS7p & GATS8p & CATS2I_ & $\begin{array}{c}\text { B10 } \\
\text { 06_PL }\end{array}$ \\
\hline IC50 & & & & & \\
\hline VE1_D & -0.290 & 1 & & & & \\
\hline VE1_B(e) & 0.166 & 0.424 & 1 & & & & \\
\hline GATS7p & -0.561 & -0.170 & -0.402 & 1 & & & \\
\hline GATS8p & 0.084 & -0.014 & 0.026 & -0.111 & 1 & & 1 \\
\hline CATS2D_06_PL & 0.512 & -0.403 & -0.251 & 0.261 & 0.360 & & \\
\hline B10[N-N] & 0.920 & -0.206 & 0.170 & -0.432 & 0.085 & 0.628 & 1 \\
\hline F08[C-C] & -0.214 & 0.718 & 0.329 & -0.218 & -0.123 & -0.557 & -0.356 \\
\hline DLS_07 & 0.036 & -0.285 & -0.131 & 0.205 & 0.204 & 0.203 & 0.089 \\
\hline Psychotic-80 & 0.079 & -0.394 & -0.356 & 0.257 & 0.147 & 0.401 & 0.177 \\
\hline cRo5 & -0.200 & 0.237 & -0.090 & 0.296 & 0.189 & 0.182 & 0.080 \\
\hline
\end{tabular}


International Journal of Trend in Scientific Research and Development (IJTSRD) ISSN: 2456-6470

\begin{tabular}{|c|c|c|c|c|}
\hline & F08[C-C] & DLS_07 & Psychotic-80 & cR05 \\
\hline F08[C-C] & 1 & & & \\
\hline DLS_07 & -0.517 & 1 & & \\
\hline Psychotic-80 & -0.723 & 0.343 & 1 & \\
\hline cRo5 & -0.341 & 0.451 & 0.453 & 1 \\
\hline
\end{tabular}

Table 4 Regression Parameters and Quality of Correlation

\begin{tabular}{|c|c|c|c|c|c|c|c|c|}
\hline $\begin{array}{c}\text { Model } \\
\text { no }\end{array}$ & $\begin{array}{c}\text { Parameters } \\
\text { Used }\end{array}$ & $\mathbf{A}_{\mathbf{i}}=(1-4)$ & $\mathbf{B}$ & $\mathbf{S E}$ & $\mathbf{R}^{2}$ & $\mathbf{R}^{2}{ }_{\text {Adj }}$ & F-ratio & Q=R/SE \\
\hline $\mathbf{0 1}$ & DLS_07 & $0.0710( \pm 0.3618)$ & 0.1155 & 0.3980 & 0.0013 & 0.0000 & 0.038 & 0.0906 \\
\hline $\mathbf{0 2}$ & Psychotic_80 & $0.0609( \pm 0.1427)$ & 0.1482 & 0.3970 & 0.0062 & 0.0000 & 0.182 & 0.1983 \\
\hline $\mathbf{0 3}$ & GATS8p & $0.4605( \pm 1.0130)$ & -0.3303 & 0.3968 & 0.0071 & 0.0000 & 0.207 & 0.2123 \\
\hline $\mathbf{0 4}$ & VE1_B_e_ & $0.7731( \pm 0.8536)$ & -2.8061 & 0.3927 & 0.0275 & 0.000 & 0.820 & 0.4223 \\
\hline $\mathbf{0 5}$ & cRo5 & $-0.2091( \pm 0.1906)$ & 0.3550 & 0.3902 & 0.0399 & 0.0068 & 1.204 & 0.5119 \\
\hline $\mathbf{0 6}$ & F08[C-C] & $-0.0125( \pm 0.0106)$ & 0.4773 & 0.3891 & 0.0456 & 0.0127 & 1.386 & 0.5489 \\
\hline $\mathbf{0 7}$ & VE1_D & $-0.4217( \pm 0.2582)$ & 2.2654 & 0.3811 & 0.0842 & 0.0526 & 2.667 & 0.7614 \\
\hline $\mathbf{0 8}$ & CATS2D_06_PL & $0.2536( \pm 0.0789)$ & 0.0978 & 0.3420 & 0.2626 & 0.2372 & 10.327 & 1.4985 \\
\hline $\mathbf{0 9}$ & GATS7p & $-3.0310( \pm 0.8296)$ & 3.4705 & 0.3296 & 0.3152 & 0.2916 & 13.348 & 1.7036 \\
\hline $\mathbf{1 0}$ & B10[N-N] & $2.0051( \pm 0.1589)$ & 0.1149 & 0.1563 & 0.8459 & 0.8406 & 159.185 & 5.8830 \\
\hline $\mathbf{1 1}$ & B10[N-N] & $2.1527( \pm 0.2031)$ & 0.1274 & 0.1554 & 0.8529 & 0.8424 & 81.195 & 5.9418 \\
& CATS2D_06_PL & $-0.0534( \pm 0.0461)$ & $: 245$ & -6470 & & 0 & & \\
\hline $\mathbf{1 2}$ & B10[N-N] & $2.0383( \pm 0.1604)$ & 0.1482 & 0.1553 & 0.8531 & 0.8426 & 81.313 & 5.9462 \\
& Psychotic_80 & $-0.0665( \pm 0.0567)$ & & & & & & \\
\hline $\mathbf{1 3}$ & B10[N-N] & $1.9578( \pm 0.1595)$ & 0.8738 & 0.1535 & 0.8565 & 0.8463 & 83.582 & 6.0286 \\
& VE1_D & $-0.1531( \pm 0.1063)$ & & & & & & \\
\hline $\mathbf{1 4}$ & B10[N-N] & $2.1064( \pm 0.1645)$ & -0.0703 & 0.1512 & 0.8608 & 0.8508 & 86.559 & 6.1352 \\
& F08[C-C]_ & $0.0076( \pm 0.0044)$ & & & & & & \\
\hline $\mathbf{1 5}$ & B10[N-N] & $1.8150( \pm 0.1588)$ & 1.3047 & 0.1409 & 0.8791 & 0.8704 & 101.768 & 6.6524 \\
& GATS7p & $-1.0902( \pm 0.3934)$ & & & & & & \\
\hline $\mathbf{1 7}$ & B10[N-N] & $2.0531( \pm 0.1161)$ & 0.3550 & 0.1139 & 0.9211 & 0.9154 & 163.392 & 8.4292 \\
& cRo5 & $-0.2881( \pm 0.0558)$ & & & & & & \\
\hline & B10[N-N] & $2.0441( \pm 0.1161)$ & 0.0110 & 0.1135 & 0.9243 & 0.9159 & 109.961 & 8.4688 \\
& cRo5 & $-0.2993( \pm 0.0566)$ & & & & & & \\
\hline & GATS8p & $0.3194( \pm 0.2959)$ & & & & & & \\
\hline
\end{tabular}


International Journal of Trend in Scientific Research and Development (IJTSRD) ISSN: 2456-6470

\begin{tabular}{|c|c|c|c|c|c|c|c|c|}
\hline 18 & $\begin{array}{l}\text { B10[N-N] } \\
\text { GATS7p } \\
\text { VE1_D }\end{array}$ & $\begin{array}{l}1.6839( \pm 0.1503) \\
-1.3914( \pm 0.3696) \\
-0.2545( \pm 0.0917)\end{array}$ & 2.8947 & 0.1266 & 0.9059 & 0.8955 & 86.651 & 7.5179 \\
\hline 19 & $\begin{array}{l}\text { B10[N-N] } \\
\text { cRo5 } \\
\text { GATS8p }\end{array}$ & $\begin{array}{l}2.0441( \pm 0.1161) \\
-0.2993( \pm 0.0566) \\
0.3194( \pm 0.2959)\end{array}$ & 0.0110 & 0.1135 & 0.9243 & 0.9159 & 109.961 & 8.4688 \\
\hline 20 & $\begin{array}{c}\text { B10[N-N] } \\
\text { cRo5 } \\
\text { DLS_07 }\end{array}$ & $\begin{array}{c}2.0418( \pm 0.1128) \\
-0.3331( \pm 0.0605) \\
0.1874( \pm 0.1127)\end{array}$ & 0.2238 & 0.1104 & 0.9284 & 0.9205 & 116.710 & 8.7250 \\
\hline 21 & $\begin{array}{l}\text { GATS7p } \\
\text { cRo5 } \\
\text { B10[N-N] }\end{array}$ & $\begin{array}{c}-0.5630( \pm 0.330) \\
-0.2518( \pm 0.0580) \\
1.9489( \pm 0.1280)\end{array}$ & & 01102 & 0.9287 & 0.9208 & 117.279 & 8.7461 \\
\hline 22 & $\begin{array}{c}\text { B10_N_N } \\
\text { F08[C-C] } \\
\text { VE1_D }\end{array}$ & $\begin{array}{c}2.1541( \pm 0.1176) \\
0.0241( \pm 0.0044) \\
-0.5575( \pm 0.1052)\end{array}$ & 2.2910 & 0.1078 & 0.9318 & 0.9242 & 122.890 & 8.9532 \\
\hline 23 & $\begin{array}{c}\text { B10[N-N] } \\
\text { cRo5 } \\
\text { GATS7p } \\
\text { Psychotic_80 }\end{array}$ & $\begin{array}{c}1.9040( \pm 0.1308) \\
-0.2806( \pm 0.0614) \\
-0.6753( \pm 0.3374) \\
0.0602( \pm 0.0459)\end{array}$ & $\begin{array}{l}1.0557 \\
\text { nd in } \\
\text { searc }\end{array}$ & 0.1087 & $\begin{array}{l}0.9332 \\
1 \mathrm{C}\end{array}$ & 0.9229 & 90.733 & 8.8833 \\
\hline 24 & $\begin{array}{c}\text { B10[N-N] } \\
\text { cRo5 } \\
\text { DLS_07 } \\
\text { F08[C-C] }\end{array}$ & $\begin{array}{l}2.1076( \pm 0.1180) \\
-0.3207( \pm 0.0595) \\
0.2707( \pm 0.1225) \\
0.0057( \pm 0.0037)\end{array}$ & $\begin{array}{l}-0.0005 \\
v: 245\end{array}$ & 0.1077 & 0.9344 & & 92.610 & 8.9744 \\
\hline 25 & $\begin{array}{c}\text { B10[N-N] } \\
\text { cRo5 } \\
\text { GATS7p } \\
\text { VE1_D }\end{array}$ & $\begin{array}{c}1.8582( \pm 0.1373) \\
-0.2114( \pm 0.0621) \\
-0.8065( \pm 0.3573) \\
-0.1343( \pm 0.0854)\end{array}$ & 1.8367 & 0.1073 & 0.9349 & 0.9249 & 93.381 & 9.0117 \\
\hline 26 & $\begin{array}{c}\text { B10[N-N }] \\
\text { DLS_07 } \\
\text { F08[C-C }] \\
\text { VE1_D }\end{array}$ & $\begin{array}{l}2.1734( \pm 0.1174) \\
0.1452( \pm 0.1155) \\
0.0272( \pm 0.0050) \\
-0.5780( \pm 0.1054)\end{array}$ & 2.1885 & 0.1067 & 0.9357 & 0.9258 & 94.543 & 9.0678 \\
\hline 27 & $\begin{array}{c}\text { B10[N-N }] \\
\text { cRo5 } \\
\text { F08[C-C }]\end{array}$ & $\begin{array}{c}2.1271( \pm 0.1163) \\
-0.1239( \pm 0.0817) \\
0.0166( \pm 0.0066)\end{array}$ & 1.7237 & 0.1053 & 0.9373 & 0.9277 & 97.182 & 9.1933 \\
\hline
\end{tabular}


International Journal of Trend in Scientific Research and Development (IJTSRD) ISSN: 2456-6470

\begin{tabular}{|c|c|c|c|c|c|c|c|c|}
\hline & VE1_D & $-0.3850( \pm 0.1533)$ & & & & & & \\
\hline \multirow[t]{4}{*}{28} & $\mathrm{~B} 10[\mathrm{~N}-\mathrm{N}]$ & $2.1824( \pm 0.1155)$ & 2.3142 & 0.1047 & 0.9380 & 0.9285 & 98.405 & 9.2508 \\
\hline & F08[C-C $]$ & $0.0308( \pm 0.0060)$ & & & & & & \\
\hline & Psychotic_80 & $0.0926( \pm 0.0571)$ & & & & & & \\
\hline & VE1_D & $-0.6044( \pm 0.1062)$ & & & & & & \\
\hline \multirow[t]{4}{*}{29} & $\mathrm{~B} 10[\mathrm{~N}-\mathrm{N}]$ & $1.9208( \pm 0.1222)$ & 0.8730 & 0.1045 & 0.9383 & 0.9288 & 98.803 & 9.2698 \\
\hline & cRo5 & $-0.2982( \pm 0.0597)$ & & & & & & \\
\hline & DLS_07 & $0.2156( \pm 0.1075)$ & & & & & & \\
\hline & GATS7p & $-0.6447( \pm 0.3162)$ & & & & & & \\
\hline \multirow[t]{4}{*}{30} & $\mathrm{~B} 10[\mathrm{~N}-\mathrm{N}]$ & $1.9399( \pm 0.1235)$ & 3.3488 & 0.0939 & 0.9502 & 0.9425 & 124.031 & 10.3859 \\
\hline & $\mathrm{F} 08[\mathrm{C}-\mathrm{C}]$ & $0.0197( \pm 0.0041)$ & & & & & & \\
\hline & GATS7p & $-0.9062( \pm 0.2920)$ & S & & & & & \\
\hline & VE1_D & $-0.5498( \pm 0.0916)$ & & & & & & \\
\hline
\end{tabular}

Table 5 observed and estimated $\mathrm{IC}_{50}$ values Using model 30 (Table 4)

\begin{tabular}{|c|c|c|c|}
\hline Model No. & Obs. plC 50 & Est. $\mathrm{pIC}_{50}$ & Residual \\
\hline $1 *$ & 0.068 & 0.12111 & -0.0531 \\
\hline $2 *$ & 0.918 & 1.88321 & -0.9652 \\
\hline 3 & 2.12 & 2.12 & 0 \\
\hline $4 *$ & 0.028 & 0.08382 & -0.0558 \\
\hline $\begin{array}{l}5 \\
\end{array}$ & S 0.102 & $6=0.053$ & 0.049 \\
\hline 6 & 0.034 & -0.011 & 0.045 \\
\hline & 0.022 & 0.204 & -0.182 \\
\hline Q: & 0.003 & -0.012 & 0.01504 \\
\hline 9 & 0.00 & 0.063 & -0.06 \\
\hline 10 & 0.011 & 0.015 & -0.004 \\
\hline 11 & 0.002 & 0.04 & -0.038 \\
\hline 12 & 0.006 & 0.033 & -0.027 \\
\hline 13 & 0.046 & 0.063 & -0.017 \\
\hline 14 & 0.004 & -0.043 & 0.047 \\
\hline 15 & 0.005 & 0.052 & -0.047 \\
\hline 16 & 0.034 & 0.108 & -0.074 \\
\hline $17 *$ & 0.041 & 0.06727 & -0.0263 \\
\hline $18 *$ & 0.009 & 0.06183 & -0.0528 \\
\hline
\end{tabular}


International Journal of Trend in Scientific Research and Development (IJTSRD) ISSN: 2456-6470

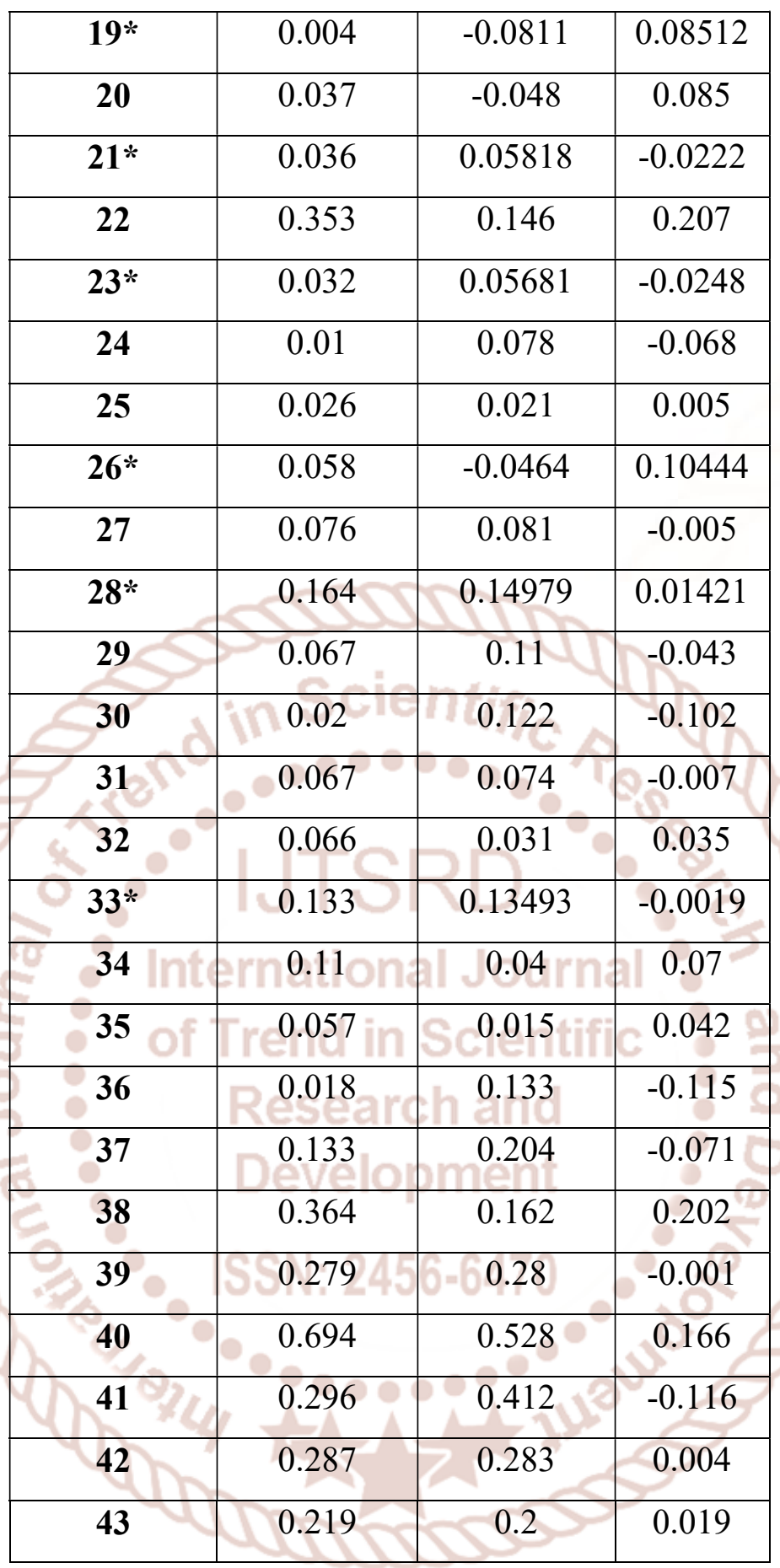

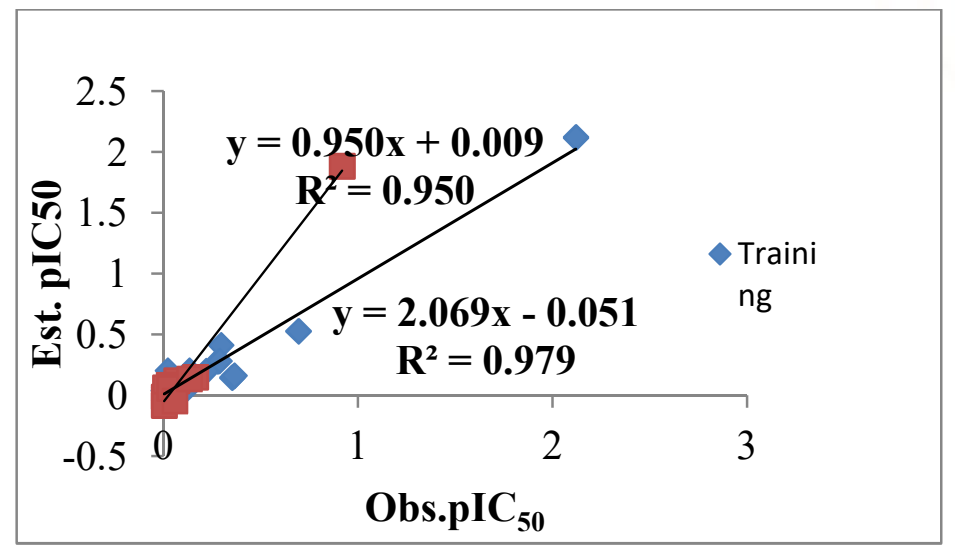

Fig.1 Correlation between observed and estimated $\mathrm{pIC}_{50}$ 
International Journal of Trend in Scientific Research and Development (IJTSRD) ISSN: 2456-6470

Table 6 Cross validated parameters for the best obtained models

\begin{tabular}{|c|c|c|c|c|c|c|c|}
\hline $\begin{array}{l}\text { Model } \\
\text { no }\end{array}$ & Parameters used & PRESS & SSY & PRESS/SSY & $\mathbf{R}_{\mathrm{cv}}^{2}$ & SPRESS & PSE \\
\hline 10 & $\mathrm{~B} 10[\mathrm{~N}-\mathrm{N}]$ & 0.709 & 3.891 & 0.182 & 0.818 & 0.156 & 0.071 \\
\hline 16 & $\begin{array}{c}\mathrm{B} 10[\mathrm{~N}-\mathrm{N}] \\
\mathrm{cRo} 5\end{array}$ & 0.363 & 4.236 & 0.086 & 0.914 & 0.114 & 0.061 \\
\hline 22 & $\begin{array}{c}\text { B10[N-N] } \\
\text { VE1_D } \\
\text { F08_C_C_ }\end{array}$ & 0.314 & 4.286 & 0.073 & 0.927 & 0.108 & 0.059 \\
\hline 30 & $\begin{array}{c}\text { B10_N_N_ } \\
\text { F08_C_C_ } \\
\text { VE1_D } \\
\text { GATS7p }\end{array}$ & & & 0.052 & 0.948 & 0.094 & 0.055 \\
\hline
\end{tabular}

Table 7 Ridge regression parameters for the best obtained models.

\begin{tabular}{|c|c|c|c|c|c|}
\hline Model no & Parameters used & VIF & T & $\lambda_{\mathrm{i}}$ & $\mathrm{K}$ \\
\hline $\mathbf{1 0}$ & $\mathrm{B} 10[\mathrm{~N}-\mathrm{N}]$ & 1.0000 & 1.0000 & 1.0000 & 1.0000 \\
\hline $\mathbf{1 6}$ & $\mathrm{B} 10[\mathrm{~N}-\mathrm{N}]$ & 1.0065 & 0.9936 & 1.080064 & 1.00 \\
& cRo5 & 1.0065 & 0.9936 & 0.919936 & 1.17 \\
\hline $\mathbf{2 2}$ & B10[N-N] & 1.1520 & 0.8680 & 1.895320 & 1.00 \\
& VE1_D & 2.0735 & 0.4823 & 0.840262 & 2.26 \\
& F08_C_C_ & 2.2741 & 0.4397 & 0.264419 & 7.17 \\
\hline & B10[N-N] & 1.6753 & 0.5969 & 1.903822 & 1.00 \\
& F08_C_C_ & 2.5824 & 0.3872 & 1.420041 & 1.34 \\
& VE1_D & 2.0750 & 0.4819 & 0.449074 & 4.24 \\
& GATS7p & 1.5276 & 0.6546 & 0.227063 & 8.38 \\
\hline
\end{tabular}

$\mathrm{VIF}=$ Variance Inflation Factor

$\mathrm{T}=$ Tolerance

$\lambda_{\mathrm{i}}=$ Eigen values

$\mathrm{k}=$ Condition number 


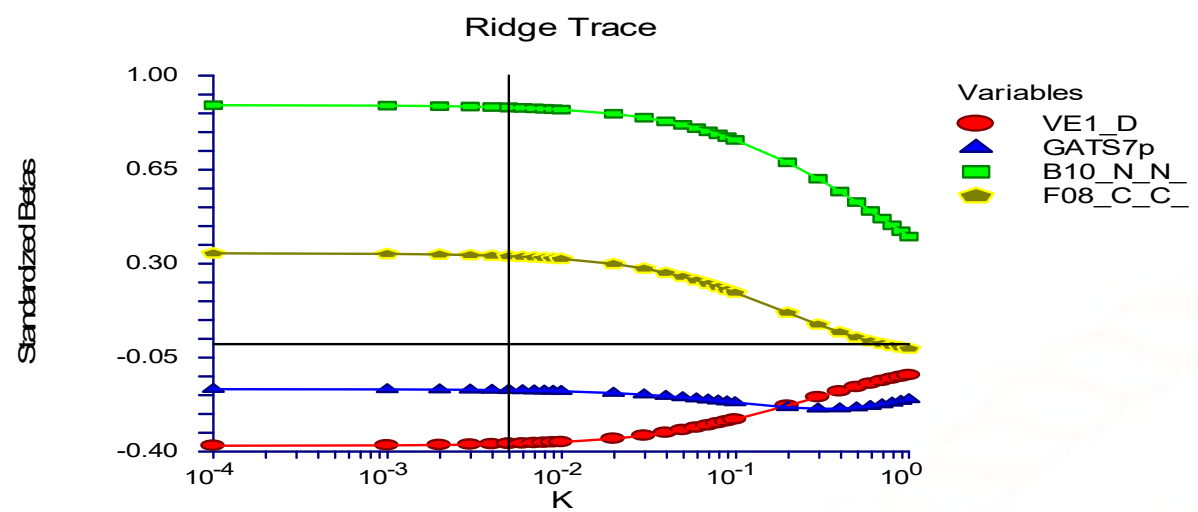

Fig.2 Ridge trace for four variable model

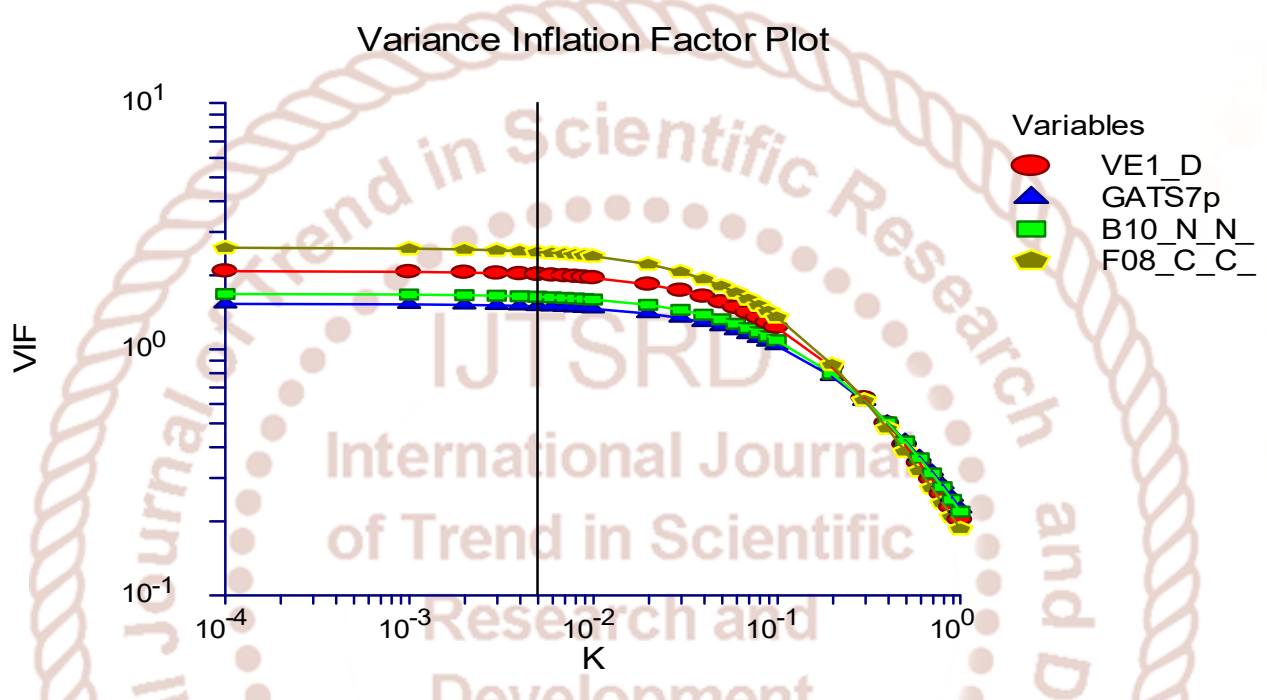

Fig. 3 VIF plot for four-variable model

\section{REFERANCE:}

1) F.Nosten,

T.Chogsuphajaisiddhi,C.Luxemburger,H.K.Webst er\&M.Edstein, L.Phaipun,K. L.Thew\& N. J. White; Lancet; 1982,331,1140.

2) A.M.Oduola,W.K.Milhous,L.A.Salako\&O.Walker ; Lancet;1987,2,1304.

3) P. Carson, C. Flanagan, C.E.Lekes\& A. Alvin; Science; $1956,124,484$.

4) P.E. Carson, C.I.Flanagan,C.E.Lakes,A.S. Alvin; Science; $1982,31,427$.

5) H.L. Schmdt,R.Frank,C.S.Genther, R.N.Rossan\&W.I. Squires; Am J Trop Med Hvg;1982,31,612.

6) J.L.Bras,R. FundanClinPharmacol;2003,17,147.

7) J.E. Hyde; Trends Parasitol;2005,21,494.
8) R.Arav-Boger, T. Shapiro; A.Anna;Rev PharmacolToxicol;2005,45,565.

9) B.P. Das, D.W. Boykin;JMedChem;1977,20,531.

10) J. Anne, E.D. Cierec, H.Eyssen\&O. Dann;AntimicrobAgentsChemother; 1980,18, 231.

11) R.R.Tidwell,C.A. Bell, J.E. Hall, D.E.Kyle,M. Grogl;Antimicob Agent Chemother; 1990,34,1381.

12) R.R.Tidwell,S.K.Jones,J.D.Geratz, K.A.Ohemeng, M. Cory, J.E. Hall; JMedChem; 1990,33,1252.

13) J.J.Brendle, A. Outlaw,A. Kumar,D.W. Boykin, D.A.Patrick,R.R.Tidwel,K.A.Werbovetz;Antimicr ob Agents Chemother;2007,46,4761.

14) P.G. Bray,M.P.Barrett,S.A.Ward,H.P. De Koning; Trends Parasitol; 2003,19.232.

15) M.Stead,P.G. Bray, I.G. Edward, H.P. De Koning, B.C.Elford, P.A. Stocks \& S.A. Wardol; Pharmacol,2001,59,2001,1298.

16) A.H.Fairlamb;TrendsParasitol; 2003,19,488. 
17) R. Docampo, S.N. Moreno; Parasitol, Res;2003,90,510.

18) R.J.Burchomore, P.O. Ogbunude,B. Enanga, M.P. Barrett; curr Pharm LDes;2002,8,256.

19) B.Shaika, T.Kaushal and V. K. Agrawal ; J. Indian Chem. Soc., 2016,93,876.

20) S.Paliwal, J.Sharma and S.Paliwal ; Indian $J$. Chem., 2012,51B,617.

21) D. Legros,G.Ollivier,M.E. Gastellu, C. Paquet,C. Burri,lancetInfec Dis,2002,2,437

22) Dragon Software for calculation of Topological Indoses,www.disat.unimib,it.

23) NCSS, statistical analysis software,www.ncss.com (Accessed May 2005)

24) S.Cheterjee, A.S.Hadi, B. Price; Regression analysis by Examples, $3^{\text {rd }}$.ed.; Wiley \&Sons:New York;6,141-153.

25) L. Pogliani,Structure Property Relationship Of Amino Acids and Some Dipeptide, Amino acids; 1994,6,141-15 